\title{
UMA VISÃO INTERDISCIPLINAR DA AIDS NA DÉCADA DE 1980: EM CENA, JORNALISMO E SAÚDE
}

\section{ENSAIO TEÓRICO}

LOPES, Pablo de Oliveira ${ }^{1}$

NEVES, Paulo Sérgio da Costa ${ }^{2}$

PEREIRA, Lucas de Almeida ${ }^{3}$

LOPES, Pablo de Oliveira. NEVES, Paulo Sérgio da Costa. PEREIRA, Lucas de Almeida. Uma visão interdisciplinar da AIDS na década de 1980: em cena, jornalismo e saúde. Revista Científica Multidisciplinar Núcleo do Conhecimento. Ano 05, Ed. 08, Vol. 09, pp. 46-69. Agosto de 2020. ISSN: 2448-0959, Link de acesso: https://www.nucleodoconhecimento.com.br/saude/visao-interdisciplinar

\section{RESUMO}

O presente artigo apresenta a Síndrome da Imunodeficiência Adquirida (SIDA, em português, ou AIDS, da sigla em inglês), quando do seu aparecimento, na década de 1980, sob uma ótica interdisciplinar: de um lado, sinais, sintomas, métodos diagnósticos e tratamento são abordados e fazem parte do modelo biomédico que participa da interpretação dessa doença; do outro, as representações da enfermidade em matérias jornalísticas publicadas no jornal O Globo, um dos mais importantes do Brasil. Saúde e Jornalismo ajudam a construir ideias e a entender conceitos,

\footnotetext{
${ }_{1}^{1}$ Doutorando do Programa de Pós-graduação em Ciências Humanas e Sociais da Universidade Federal do ABC; Mestre em Ciências Humanas pela Universidade Santo Amaro.

${ }^{2}$ Orientador. Doutorado em Sociologia e Ciências Sociais. Mestrado em Sociologia e Ciências Humanas. Graduação em Ciências Sociais.

${ }^{3}$ Coorientador. Doutorado em História. Graduação em História.
} 
preconceitos e estigmas que recaíam e ainda recaem sobre a moléstia que ficou conhecida como a peste gay, uma das várias denominações atribuídas à AIDS quando ela surgiu. Discute-se se é possível compreender o processo saúde-doença a partir de uma perspectiva plural, que ultrapasse os limites da Medicina. Para tanto, analisase textos do jornal O Globo, que tratam do binômio HIV/AIDS, dispensando atenção especial à linguagem e à lexicografia usadas na elaboração dos mesmos, e leva-se em consideração a visão médica acerca da doença nos anos 1980. O trabalho permite-nos concluir que é possível e necessário encarar o processo saúde-doença usando não somente os fenômenos biológicos, mas recorrendo a aspectos sociais, econômicos, políticos e ambientais, diante de vários campos disciplinares.

Palavras-chave: HIV/AIDS, divulgação científica, jornalismo científico, interdisciplinaridade.

\section{INTRODUÇÃO}

AIDS ou SIDA ì a sigla usada para a Sndrome da Imunodeficiencia Adquirida, uma doenca caracterizada por grave disfuna do sistema imunológico dos indivduos infectados pelo Virus da Imunodeficiéncia Humana (HIV). Segundo o Protocolo Clínico e Diretrizes Terapéuticas para Manejo da Infecrajo pelo HIV em Adultos (2018), sua evoluço pode ser dividida em três fases: Infeça aguda (a Sndrome Retroviral Aguda - SRA), que pode surgir algumas semanas apis a infeço inicial, com manifestapes como febre, calafrios, sudorese, mialgia, cefalia, dor de garganta, sintomas gastrointestinais, linfadenopatias generalizadas e erupies cutineas. A maior parte dos individuos apresenta sintomas autolimitados, que desaparecem apis algumas semanas. Entretanto, a maioria nào é diagnosticada devido à semelhança com outras doenças virais; Infecmo assintomática, de durạ́o varível, podendo chegar a alguns anos, e doenca sintomática, da qual a AIDS é a sua manifestạio mais grave, que ocorre na medida em que o paciente vai apresentando alterames mais acentuadas da imunidade, e aparecem infecpies oportunistas e neoplasias.

De acordo com o Protocolo Clnico e Diretrizes Terapéuticas para Manejo da Infeçao pelo HIV em Adultos (2018), as infecpies oportunistas, como tuberculose pulmonar 
atpica ou disseminada, pneumonia por Pneumocistis jiroveci, toxoplasmose cerebral, candidiase oroesofágica, meningite por criptococos e retinite por citomegalovirus surgem nessa fase. Tumores raros em indivduos imunocompetentes, como o Sarcoma de Kaposi e certos tipos de linfoma, podem ocorrer também. O agente etiológico é um vrus RNA, retrovirus, atualmente denominado Virus da Imunodeficiência Humana (HIV), com 2 tipos conhecidos: o HIV-1 e o HIV-2. Antes de 1986, era denominado HTLV-III/LAV.

A enfermidade pode ser transmitida por via sexual, sangunea (via parenteral) e da mäe para o filho, no curso da gravidez, durante ou apís o parto, e pelo aleitamento materno no perodo pós-parto. Säo fatores de risco associados aos mecanismos de transmissio do HIV: variapies frequentes de parceiros sexuais sem uso de preservativos, presença de outras doenças sexualmente transmissveis, utilizaça de sangue ou seus derivados sem controle de qualidade, compartilhamento ou uso de seringas e agulhas näo esterilizadas (como acontece entre usuários de drogas injetáveis), gravidez em mulher infectada pelo HIV e transplante de órgäos ou recepcáo de símen de doadores infectados. É importante ressaltar que o HIV náo é transmitido pelo convivio social ou familiar, abrạ̧o ou beijo, alimentos, água, picadas de mosquitos ou de outros insetos. Tal informacáo é importante, mesmo nos dias de hoje, pois atua na reduçáo da ignorància e do preconceito sobre as pessoas que vivem com HIV/AIDS.

Após a explanação da parte biomédica que envolve a temática desse texto, cabe ressaltar que para a discussão das informações publicadas sobre a AIDS, na década de 1980, foi escolhido o jornal O Globo, devido à influência que ele exerce sobre o discurso da imprensa brasileira. O Globo está entre os veculos de maior circulacia no pas e ocupa, portanto, posiạo importante na divulgaăo das notcias e na possivel reproducăo de esterétipos e disseminaça de preconceitos. Apesar de ser publicado no Rio de Janeiro, a penetracio em outros estados brasileiros transporta a retórica de seus jornalistas para diversas regiies do território nacional.

Usando as ferramentas de busca do site do jornal O Globo e empregando as palavraschave 'AIDS', 'gay', 'homossexuais', 'preconceito' e 'discriminậa' selecionamos, 
aleatoriamente, textos jornalsticos da década de 1980 e do começo da década de 1990, voltados aos homossexuais e ao HIV-AIDS, e os analisamos com base na semantica das palavras. Verificamos a presença de estereotipos ou fatos que caracterizam a formaño de preconceitos em relạa às pessoas que viviam com $\mathrm{HIV} \mathrm{e}$ AIDS.

É possvel desenvolver um estudo com base no inventário cronológico dos vocábulos, buscando seus significados de acordo com os valores impostos pelo discurso discriminatório de quem os utiliza. O estudo do léxico pode indicar a mentalidade de uma determinada época. Sendo assim, a reflexäo sobre os textos publicados no jornal impresso recairá sobre a semảntica das palavras. Palavras assumem conotañes distintas na dependência do contexto em que sio empregadas e da ideologia de quem as usa. Noções, conceitos, comportamentos, atitudes e polticas públicas sio influenciados por discursos, cujas estruturas dependem dos vocábulos usados e do que significam. Isso se aplica à disseminação de preconceitos e de estereótipos sobre determinados grupos populacionais, como é o caso dos homossexuais. A partir dessa premissa, analisamos os textos jornalisticos da década de 1980, considerando a abordagem dispensada à AIDS e aos homossexuais, naquele perodo histórico, a partir da desconstrup̣o dos discursos, como sistematizado por Tucci Carneiro (1994).

\section{MEDICINA E JORNALISMO: REPRESENTAÇÕES DA AIDS NOS HOSPITAIS E NAS BANCAS DE JORNAIS}

A primeira reportagem de $\mathrm{O}$ Globo que destacamos apontava no ttulo a falta de conhecimento dos próprios médicos a respeito da doença: "Heusi nà punirá legistas que se negam a necropsiar os aideticos." (O GLOBO, 1987, p. 9). A materia informa que os legistas do Instituto Médico Legal (IML) que se negassem a realizar a necrópsia do corpo do preso Luciano Alves Azeredo, que morreu de AIDS, náo seriam punidos. A declaracạo foi feita por Marcos Heusi, Secretário de Poĺcia Civil na ocasiäo, e desvela como o discurso das autoridades tratava a doença e suas vitimas. O avaņ̧o da ciência rumo ao entendimento da enfermidade permitiu que dividas fossem esclarecidas e que, em tese, situañes como essa nào se repetissem. A falta de 
conhecimento e domnio sobre a doença tornava os profissionais de saide potenciais disseminadores de esterétipos e de estigmas. Médicos e enfermeiros podiam exercer um papel ambguo e até contraditório do ponto de vista social e ético: cuidar, apoiar, mas podendo discriminar também.

Contribuindo ainda mais para uma reflexäo, o texto da mesma matéria, de 24 de junho de 1987, acrescenta alguns comentários e questionamentos, informando ser compreensvel o temor de contágio dos médicos do IML, mas demonstrando inconformidade para com o fato de os médicos, àquela altura, ainda desconhecerem o tamanho do perigo de contágio durante uma necrópsia. A reportagem ainda coloca em dúvida a autenticidade dos atestados de óbito dados e da confiança que se poderia depositar nas estatísticas sobre a sndrome. Por fim, faz-se uma indagação que pie em xeque as políticas piblicas do Brasil na época: "existe de fato no Brasil um plano oficial anti-AIDS que realmente cubra todos os aspectos do problema?". (O GLOBO, 1987, p. 9).

A pergunta tinha pertinéncia para o perodo, já que se tratava de uma fase em que pouco se sabia sobre a doenca. Tudo era novo, cercado de dívida. As polticas públicas, incipientes, náo transmitiam segurança à populạ̣o. Segundo Marques (2002), o perodo compreendido entre 1987 e 1989 foi aquele em que o Programa Nacional de AIDS realmente se desenvolveu. A coordenapa nacional centralizou as apies e afastou-se dos programas estaduais e ONGs. Estas, por sua parte, ganharam espało e destaque ao longo dos anos e exerceram papel significativo na discussio do Programa Nacional.

A resposta oficial no nvel nacional, no enfrentamento à epidemia de AIDS, finalmente comerou a ser construida, isso quase dois anos depois que o ministro da Saide a reconheceu como um problema de saide piblica emergente no pas (maio de 1985). (MARQUES, 2002, p. 53).

Retomando a descriço da enfermidade, destaca-se o perodo de incubapa, aquele compreendido entre a infecyo pelo HIV e a fase aguda ou o aparecimento de anticorpos circulantes. Segundo o Ministério da Saíde, por meio da Série Cadernos de Atenóo Bísica (2002), para a grande maioria dos pacientes, esse perodo varia 
entre 1 e 3 meses, apis o contato infeccioso, podendo ocasionalmente chegar a 6-12 meses em alguns poucos casos relatados na literatura médico-cientfica. Conforme o Protocolo Clnico e Diretrizes Terapéuticas para Manejo da Infeça pelo HIV em Adultos (2018), perodo de laténcia é aquele compreendido entre a infeçao pelo HIV e os sintomas e sinais que caracterizam a doenca causada pelo HIV (AIDS). Estima- se que o tempo médio seja de dez anos. O perodo de transmissibilidade é variável, mas 0 indivduo infectado pelo HIV pode transmitir o vrus durante todas as fases da infecio, sendo esse risco proporcional à magnitude da viremia e à presença de outros cofatores.

Sobre o diagnístico, a detecáo laboratorial do HIV é realizada por meio de técnicas que pesquisam ou quantificam anticorpos, antgenos, material genético por técnicas de biologia molecular (carga viral) ou isolamento direto do vrus (cultura). Na prática, os testes que pesquisam anticorpos (sorologicos) sio os mais utilizados. $O$ aparecimento de anticorpos detectaveis por testes sorologicos ocorre num perodo médio de 6 a 12 semanas da infeço inicial. Denomina-se 'janela imunologica' esse intervalo entre a infeça e a detecpo de anticorpos por técnicas laboratoriais convencionais. Durante esse perodo, as provas sorologicas podem ser falsonegativas. Devido à importảncia do diagnóstico laboratorial, particularmente pelas consequências de se 'rotular' um individuo como HIV positivo e para se ter uma maior segurança no controle de qualidade do sangue e derivados, de acordo com a Série Cadernos de Atenạo Básica (2002), recomenda-se que os testes de deteḉo laboratorial eventualmente reagentes em uma primeira amostra sejam repetidos e confirmados conforme normatizạ́o estabelecida pelo Ministério da Saúde[4].

Nảo há cura para a AIDS; mas, nos últimos anos, foram obtidos grandes avanjos no conhecimento da patogénese da infeçáo pelo HIV; várias drogas antirretrovirais foram desenvolvidas e se mostraram eficazes no controle parcial da replicapio viral, diminuindo a progressio da doença e levando a uma reducáo da incidencia das complicañes oportunistas. Houve aumento da sobrevida, bem como uma significativa melhora na qualidade de vida dos individuos. Segundo dados da Série Cadernos de Atenọo Básica do Ministério da Saíde (2002), em 1994, foi comprovado que o uso 
da Zidovudina (AZT) pela gestante infectada durante a gestaạ, bem como pelo recém-nascido, durante as primeiras semanas de vida, pode levar a uma reduṇo de at́é 2/3 no risco de transmissio do HIV da mäe para o filho.

A partir de 1995, o uso da monoterapia foi abandonado, passando a ser recomendaño do Ministério da Saide a utilizặo de terapia combinada com duas ou mais drogas antirretrovirais para o controle da infecpa crónica pelo HIV. Atualmente, a terapia antirretroviral padrä[5] recomendada é de tris ou mais drogas, sendo o uso de terapia dupla uma situano excepcional (certas situañes de quimioprofilaxia para exposiço ocupacional). Sảo numerosas as possibilidades de esquemas terapéuticos indicados pela Coordenạo Nacional de DST e AIDS. "Näo menos importante é enfatizar que o Brasil é um dos poucos pases que financia integralmente a assisténcia ao paciente com AIDS na rede pública de saide." (BRASIL, 2002, p.13).

Segundo o Protocolo Clinico e Diretrizes Terapéuticas para Manejo da Infecpa pelo HIV em Adultos (2018), deve-se estimular o incio da TARV para todas as pessoas vivendo com HIV, independentemente da contagem de LT-CD4+. Já no Protocolo Cĺnico e Diretrizes Terapéuticas para Manejo da Infeçáo pelo HIV em Adultos de 2013, apontou-se um estudo prospectivo em uma coorte africana com 3.381 casais heterossexuais sorodiscordantes, em que 349 indivduos iniciaram tratamento durante o perodo de seguimento. Somente um caso de transmissio ocorreu nas parcerias dos participantes que estavam em tratamento e 102 nas parcerias em que a pessoa infectada pelo HIV náo estava em tratamento. Isso representa redupáo de $92 \%$ no risco de transmissio.

Ainda segundo o Protocolo Clinico (2013), mais recentemente, tornaram-se públicos os resultados do estudo HPTN052, o primeiro ensaio clinico randomizado, que avaliou a transmissio sexual do HIV entre casais sorodiscordantes. Foram randomizados 1.763 casais com contagem de LT-CD4+ entre 350 e 550 células $/ \mathrm{mm} 3$, para incio imediato do tratamento ou para iniciá-lo, quando a contagem de LT-CD4+ estivesse abaixo de 250 células $/ \mathrm{mm} 3$. Durante o estudo, ocorreram 39 episidios de transmissio, dos quais 28 foram virologicamente vinculados ao parceiro infectado; 
apenas um episidio ocorreu no grupo de terapia precoce, observando-se diminuịa de 96\% na taxa de transmissio, quando a pessoa que vive com HIV iniciava tratamento com contagem de LT-CD4+ entre 350 e 550 células $/ \mathrm{mm3}$.

De acordo com o Protocolo Clnico e Diretrizes Terapéuticas para Manejo da Infeço pelo HIV em Adultos (2018), a TARV poderá ser iniciada desde que a pessoa que vive com HIV seja devidamente informada dos benefcios e riscos relacionados a ela, além de fortemente motivada e preparada para o tratamento, respeitando-se a autonomia do indivduo. Ênfase deve ser dada ao fato de que a terapia náo deverá ser interrompida.

Em consonảncia com o Protocolo 2018, a terapia inicial deve sempre incluir combinapies de trés antirretrovirais, sendo dois inibidores de transcriptase reversa análogos de nucleośdeo (ITRN)/inibidores de transcriptase reversa análogos de nucleotdeos (ITRNt), associados a um inibidor da transcriptase reversa nảo-análogo de nucleosideo (ITRNN) ou inibidor de protease com reforco de ritonavir (IP/r) ou inibidor de integrase (INI). Como regra, o esquema de primeira linha deve ser o seguinte: Tenofovir (TDF), Lamivudiva (3TC) e o Dolutegravir (DTG), um INI.

Outro aspecto importante do tratamento $\dot{a}$ a adesáo, um processo dinámico e multifatorial que abrange aspectos f́sicos, psicologicos, sociais, culturais e comportamentais e que envolve decisies compartilhadas entre a pessoa que vive com HIV, a equipe de saide e a rede social. A adesio a um medicamento envolve sua tomada na dose e frequência prescritas. Por outro lado, além do uso correto de medicamentos a adesio ao tratamento, compreendida de modo integral, envolve também a realizậo de exames e consultas conforme solicitados. A má adesæa éuma das principais causas de falha terapéutica. Näo foi estabelecida uma relạ̣o direta entre nveis de adesio e efiḉcia dos diferentes antirretrovirais, entretanto "a maioria dos estudos aponta como necessária a tomada de pelo menos $80 \%$ das doses para que se obtenha resposta terapéutica adequada." (Protocolo Clnico e Diretrizes Terapéuticas para Manejo da Infeçáo pelo HIV em Adultos, 2013, p.53). 
É muito importante que o paciente conhę̧a as caratersticas da doença e entenda claramente o objetivo da terapia antirretroviral para participar da decisio de iniciá-la, compreendendo a relevància do uso continuado e correto do medicamento, a fim de atingir uma adequada supressáo da replicapa virológica. Para tanto, torna-se indispensivel que o paciente tenha conhecimentos básicos sobre a doença, as formas de transmissio, o significado e a utilidade dos exames laboratoriais (como a contagem de linfícitos T-CD4 e a carga viral) e os possiveis efeitos adversos em curto e longo prazo relacionados a terapia. Tendo acesso is informapies, o paciente se fortalece para enfrentar as adversidades trazidas pela doença e seu tratamento. A avaliạo médica e psicossocial do paciente permite identificar os modos de enfrentamento, as dificuldades de aceitapio e de viver com o diagnóstico positivo para HIV. A equipe de saide deve levar em considerạa esses aspectos na elaborạa do plano terapéutico. "O autocuidado também está relacionado a viver muito e estar bem, e a falta dele, de igual forma, resulta em doença e morte." (GOMES; SILVA; OLIVEIRA, 2011, p.6).

A preven a da transmissio sexual baseia-se na informaño e na educapa, sendo a profilaxia combinada o grande trunfo no combate à doença.

Por sua vez, a prevenạo da transmissio sangunea tem como diretrizes: a) transfusio de sangue: todo o sangue para ser transfundido deve ser obrigatoriamente testado para detecáo de anticorpos anti-HIV. A exclusáo de doadores em situacáo de risco aumenta a segurança da transfusio, principalmente por causa da 'janela imunologica'; b) hemoderivados: os produtos derivados de sangue, que podem transmitir o HIV, devem passar por processo de tratamento que inative o vrus; c) injeções e instrumentos pérfuro-cortantes: quando náo forem descartáveis, devem ser meticulosamente limpos para depois serem desinfetados e esterilizados. Os materiais descartáveis, apís utilizados, devem ser acondicionados em caixas apropriadas, com paredes duras, para que acidentes sejam evitados. O HIV í muito sensivel aos métodos padronizados de esterilizano e desinfeça (de alta eficícia). O virus inativado por intermédio de produtos quimicos especficos e do calor, mas náo é inativado por irradiaço ou raios gama; d) doậo de símen e órgáos: rigorosa triagem 
dos doadores; f) transmissio perinatal: uso de Zidovudina no curso da gesta áo de mulheres infectadas pelo HIV, de acordo com esquema padronizado pelo Ministério da Saíde, associado à realizạa do parto cesáreo, oferece menor risco de transmissio perinatal do virus. No entanto, a preven melhor abordagem para se evitar a transmissio da mäe para o filho.

A questio da transmissío sangunea do HIV é destacada em uma matéria de O Globo, em 15 de fevereiro de 1987, que apontava: "Risco de Aids em transfusio apavora pacientes." (BERTOLA, 1987, p. 21). O texto do jornal aborda o temor de pacientes, sobretudo hemoflicos, que viam nas transfusies uma das formas avassaladoras de expansio da doença no pas, que nào contava com adequado controle do sangue transfundido. Ponderajo plausvel e necessária, que deveria acompanhar outros aspectos, como a informaño de que outras enfermidades também podem ser transmitidas via hemotransfusio. Na ocasiao, o medo de se contrair o HIV era táo grande, que era possvel esquecer que as hepatites $B$ e $C$, por exemplo, podem ser contradas durante tal procedimento médico. É o que indica a mesma matéria: "A Aids é apenas uma das muitas doenças causadas por uma transfusio mal feita." (BERTOLA, 1987, p.21).

Diante de todas as dificuldades inerentes ao diagnóstico da infeça pelo HIV, mais uma se impie: segundo o Ministério da Saide, com base no Protocolo Clinico e Diretrizes Terapéuticas para Manejo da Infecia pelo HIV em Adultos (2013), o risco de suicdio em pacientes infectados í tris vezes maior do que na populạ́o geral. Um estudo de revisio mostrou que $26,9 \%$ das pessoas vivendo com HIV relataram ideacio suicida, sendo que 6,5\% atribuem tal ideaco a efeitos colaterais dos antirretrovirais; $22,2 \%$ tinham um plano de suicdio; 23,1\% alegaram ter a intenáo de se matar; $14,4 \%$ manifestaram desejo de morte e 19,7\% praticaram suicdio (sendo $11,7 \%$ deles com AIDS e $15,3 \%$ em outras fases da doença).

É válido destacar que, apesar de alguns pacientes relatarem ideap̧o suicida como efeito colateral dos antirretrovirais, um estudo realizado, na Suça, mostrou que pacientes submetidos a tratamento antirretroviral tém menos risco de cometerem 
suicdio do que aqueles que náo fazem uso de medicañes. $\mathrm{O}$ uso dos antirretrovirais prolonga a vida das pessoas vivendo com HIV, dando a elas mais qualidade.

O panorama exposto apresenta a realidade das pessoas vivendo com HIV e dos profissionais de saide que cuidam de tais pacientes. Uma enfermidade com multiplas manifestapjes clnicas, medicamentos com efeitos colaterais diversos e vários aspectos a serem considerados na escolha do tratamento, a AIDS exige uma visio holstica do paciente, que deve ser encarado como um individuo único, com caractersticas fsicas, comportamentais e emocionais que o diferem dos outros. A complexidade da doenca a torna um vasto e fertil campo para a construpáo de representap̃es sociais. Para Gomes; Silva e Oliveira (2011), a reflexäo sobre a disseminapio da AIDS exige considerar as transformañes dessa epidemia em seu contexto historico, sobretudo em relaño is formas de transmissio, as tendencias de vulnerabilidade à doença e aos significados construidos para enfrentar essa realidade.

Manifestapies clinicas como a perda de peso e a diarreia enfraquecem o paciente e o tornam mais frágil, vulnerável e sujeito a intercorrèncias fsicas e psicológicas. Tais manifestapies clnicas podem limitar o convivio social de maneira significativa, com repercussies f́sicas e psicologicas importantes, servindo de gatilho para o estigma e a construmo de representapies no imaginário coletivo. Homossexualidade e perda de peso sio, por exemplo, duas variaveis que podem conduzir a um estereotipo. Muitos gays ja foram rotulados como portadores de AIDS pura e simplesmente por serem magros. A magreza nao necessariamente advém da doença, mas a imagem estereotipada do homossexual promscuo, que náo preserva a própria saide, já rendeu tal sentenca a muitos. A medicina contribuiu oficialmente, ainda que de maneira involuntária, para a disseminạa de preconceito e discriminạ́o. Sobre essa associaça entre doença e AIDS, Lucinha Araijo declarou, em entrevista ao jornal O Globo, que:

atualmente, nenhum artista pode ficar doente, porque logo se especula que ele esteja com Aids. Como a senhora về esse estigma? É o preł̧o da fama. As pessoas públicas sào muito expostas. Vocé luta para ser conhecido e no dia em que é conhecido perde a privacidade. Hoje, qualquer artista que emagrȩ̣a está com Aids. (LUCAS, 1990, p.7). 
Mais do que o preço da fama, é o prȩ̣o do esterétipo. Näo só os artistas passaram por isso. Desconhecidos, anónimos, gente que näo ocupava lugar destacado na midia também foi alvo de tal especulacăo. Magros e doentes. Segregados e rotulados pela aparência fsica que tinham.

Para Gomes; Silva e Oliveira (2011) existem diversos fatores que exigem uso adequado dos antirretrovirais, que levam, muitas vezes, ao abandono do tratamento. Um dos motivos que provocam tal atitude relaciona-se aos efeitos colaterais dessas drogas, especialmente à alteracáo da imagem corporal que pode caracterizar as pessoas soropositivas como 'aidéticos', devido à lipodistrofia.

Segundo Seidl e Machado (2008), o uso do termo lipodistrofia relacionado à Sindrome da Imunodeficiência Adquirida teve incio no fim dos anos 90 e referia-se à perda de gordura subcutânea na face e nos membros superiores e inferiores de pessoas com HIV submetidas ao tratamento antirretroviral com os inibidores de protease. Ainda de acordo com Seidl e Machado (2008), estudiosos têm constatado que a lipodistrofia pode ocasionar dificuldades psicologicas e emocionais relevantes para as pessoas afetadas. "A lipodistrofia associada ao HIV acomete 40 a 50 por cento dos pacientes infectados pelo virus." (DIEHL, 2008, p.658).

O termo 'aidético', tảo carregado de simbologia, ainda está presente no vocabulário, nos pensamentos e nas construpies discursivas de alguns indivduos. Palavra negativa usada em reportagens do jornal na década de 1980, como a publicada por O Globo em 29 de maio de 1988, de autoria de Fanny Zygland. O vocábulo näo constava do ttulo: "Famlias rejeitam doentes com Aids", mas era citado já no primeiro parágrafo: "À medida que os casos de Aids se multiplicam pelo Pas, amplia-se também a rejeicáo pelos aidéticos." (1988, p.10). O texto de O Globo acrescenta ainda que o problema se tornava mais grave, quando se verificava que, após cinco anos do surgimento dos primeiros casos da doença, o Brasil náo dispunha de nenhuma poltica de acolhimento aos pacientes rejeitados por suas familias.

A rejeiço aos doentes aparecia no verbo usado - 'rejeitar'-, que significa repelir, recusar, e também no termo 'aidético'. Àquela época, a expressäo nảo era 
considerada politicamente incorreta e ainda ocupava grande espaço na preferencia de jornalistas das mais diversas redaives.

\section{O PAPEL DO MÉDICO NA PERPETUAÇÃO DO PRECONCEITO}

Em 12 de junho de 1987, reportagem de Eliane Lobato, estampada no Segundo Caderno de O Globo, traz o ttulo "Nem tudo é drama" e parte do texto carrega o significado da doença na ocasia: "Mas Aids, ao contrário, significa morte, portanto, fim dos dias, noites-trevas." Para além destas representapjes, a matéria acrescenta: "Há 4 anos, a Aids era sinónimo de peste gay." (1987, p.5). A denominạ́o 'peste gay' atravessa discursos e representavies sociais, ainda que a matéria passe a mensagem de desaparecimento da associạa entre gays e AIDS.

Aquela época, em que Aids era sinónimo de peste gay, a peła tinha um justificivel sentido didático. Hoje entra em cartaz "Por que eu?", a mesma peca de Hoffman, que foi traduzida por Luis Fernando Verssimo e Luiz Fernando Tofanelli e que Roberto Vignati dirige no Teatro da Praia. $O$ momento $\dot{e}$ bem outro: Aids náo $\dot{e}$ mais restrito aos homossexuais e tornou- se um temor na vida de todas as pessoas. (LOBATO, 1987, p.5).

Conforme já mencionado anteriormente, em junho de 1981, o Centro de Controle de Doencas dos Estados Unidos registrou os primeiros casos da enfermidade considerada à época uma incógnita. Em 1982, ela recebe o nome provisório de 'Doença dos $5 \mathrm{H}$ ', em razáo de casos identificados em homossexuais, hemoflicos, haitianos, heroinomanos - usuários de herona injetável - e prostitutas - hookers - em inglés. Denominạ́o provisória, igualmente carregada de estigma e preconceito. llustrando tal contexto, aparece outra matéria de O Globo, intitulada "Aids: entre estigma e pảnico cresce a incidencia", cujo texto traz: "Discriminaajo e pảnico. Essas sło as duas tendéncias predominantes na populapio ao falar sobre a Aids." E ainda ressalta: "Por falta de informạo, a maioria das pessoas acredita que um simples aperto de máo transmite a doença. Outros acham que somente a prática homossexual dissemina o vrus." (1985, p. 20). 
A materia, que dedica parte do texto para ressaltar a preocupapo das autoridades em acabar com o estigma da AIDS, destaca: "Cáncer gay aumentou discriminapa táo velha quanto história do homem. A discriminạjo contra homossexuais já existia, mas aumentou bastante desde que surgiu a Aids, estigmatizada como cáncer gay." ( $\mathrm{O}$ GLOBO, 1985, p.20).

A reboque da problemática abordada no Globo, cabe apontar que o estigma e o preconceito social sáo atitudes geradas, em grande medida, pelo temor do contágio e pela falta de informana, que provocam desconforto e sofrimento nas pessoas que vivem com o HIV, alvos do menosprezo social. Temas que refletem essa representạ́o social sảo o afastamento das pessoas, dos amigos, a rejeiạo ao contato fsico (aperto de máo, beijo no rosto).

Como forma de evitar que a Medicina contribua para a perpetuặo de marcas pejorativas e atribua a pessoas ou a grupos populacionais caractersticas que possam ofendê-las, causando problemas de cunho psicolígico e emocional, torna-se relevante destacar um aspecto relacionado ao atendimento médico: a humanizạa. "Com todas as vantagens da globalizạa, verificamos, ao mesmo tempo, entristecidos, o distanciamento entre as pessoas. Cada vez é mais comum ver médicos e pacientes dando lugar a numeros, exames." (LOPES, 2017, p. 1).

Segundo Gallian (2001), o processo de desumanizạa é consequência da separaço entre a Medicina e as humanidades, que aconteceu a partir do fim do século XIX. Entender o desenvolvimento histórico, recolocando as ciéncias humansticas no contexto da formacio é essencial para a (re)humanizaño da Medicina. Ainda de acordo com o autor, a Medicina ocidental era uma ciéncia essencialmente humanstica. Baseada na filosofia da natureza e com sistema teórico voltado para uma visio holstica, compreendia o homem como um ser dotado de corpo e esprito. As doenças náo eram consideradas apenas um problema especial, mas como parte de uma realidade maior, pois como afirma, "as causas das doenças, portanto, deveriam ser buscadas ná apenas no órgäo ou mesmo no organismo enfermo, mas também e principalmente no que hà de essencialmente humano no homem: a alma." (GALLIAN, 2001, p. 1). 
O médico clássico era, portanto, um filósofo; alguém que entendia as leis da natureza e da alma humana. O médico deveria ser, fundamentalmente, um humanista. Um profissional que levava em conta os aspectos biológicos, ambientais, culturais, sociológicos, familiares, psicologicos e espirituais para diagnosticar e iniciar o tratamento de uma doença. O médico de hoje, um cientista, um técnico, nảo encara o paciente com tal visio: profunda, ampla e humanstica. Claro, há excep̉es, mas elas sảo cada vez mais raras, já que a formaño médica, o curso de graduaça, nảo dádestaque ao ensino multidisciplinar.

A despeito do rápido desenvolvimento do chamado método experimental (método cientfico), durante o século XIX, a visào humanstica da Medicina seguiu preponderando e contribuindo para a formạ́o médica. O médico era um profundo conhecedor do conteido, mas também amante da literatura, da filosofia e da história. "Homem culto, o médico romảntico aliava seus conhecimentos cientficos com os humansticos e utilizava ambos na formulạa dos seus diagnósticos e prognósticos." (GALLIAN, 2001, p. 2). O médico mantinha grande proximidade com seus pacientes e com os familiares deles. $O$ auténtico médico de familia sabia que curar nào era algo meramente técnico, mas envolvia questies psicologicas, sociais, culturais e religiosas.

Entretanto, ainda no século XIX, este que consagrou a Medicina como uma atividade marcada pela humanizano, viram-se importantes descobertas em campos como o da microbiologia iniciarem uma revoluạo no terreno da patologia, gerando profundas transformañes na ciéncia médica. O desenvolvimento das análises laboratoriais e de outros métodos clnicos transformaram os métodos diagnísticos e a penicilina apareceu como grande estrela no tratamento de infecwes. "Assistia-se a um verdadeiro milagre e, ao se iniciar o século $\mathrm{XX}$, tudo dava a entender que a medicina estava prestes a atingir a sua idade de ouro, o seu estágio de 'ciéncia exata'." (GALLIAN, 2001, p. 2-3).

Os avanłos atingidos no campo tecnológico transformaram a formặo e atuaạo do médico, que passou a valorizar principios diferentes daqueles existentes no século XIX. "História, literatura e filosofia náo deixavam de ser ciéncias importantes, mas para 
- médico pouco podiam acrescentar agora que as novas descobertas e métodos efetivamente cientficos abriam novas dimensies." (GALLIAN, 2001, p. 3). A valorizaño e o estudo minucioso e sistemático do comportamento f́sico-quimico dos órgáos, tecidos e células ganharam espạ̧o. A Medicina deixava de se apoiar nas ciências humanas para se sustentar, primordialmente, nas ciências exatas e biologicas.

Para Gallian (2001), o processo de supervalorizapa dos meios tecnológicos, que acompanhou o desenvolvimento da medicina nas iltimas décadas, acarretou a 'desumanizaạo do médico'. O profissional tornou-se cada vez mais em um técnico, um especialista, profundo conhecedor de exames complexos; mas, por vezes, ignorante quanto aos aspectos humanos do paciente. $E$ isso acontece ou aconteceu náo só por exigência da formạ̣o cada vez mais especializada, mas também por conta das mudanças nas condip̉es de trabalho, que tenderam a proletarizar o mé- dico, limitando seu tempo para estar com o paciente, dando-Ihe atenต́o.

Atender a muitos pacientes, lidar com filas intermináveis de pessoas, nảo sucumbir diante da falta de medicamentos ou outros insumos necessários à boa prática médica: isso faz parte do cotidiano de muitos profissionais. Sob esse prisma, talvez seja possivel entender uma das razies pelas quais o médico abandonou a humanizaça. A melhoria do Sistema Único de Saíde passa náo somente pela maior disponibilidade de recursos financeiros e pelo investimento em capacitạ́o técnica, mas igualmente pela humanizạa do atendimento.

\section{O DESEMPENHO DA IMPRENSA NA CONSTRUÇÃO DE SENTIDOS}

Pode-se dizer que a ignorancia sobre a doença contribui para a reprodupa de estereótipos. A imprensa por vezes ocupa papel central nessa história, mas também pode desempenhar outra funcio: a de esclarecer.

Segundo Darde (2006), a imprensa brasileira desempenhou um papel fundamental na construp̣o de sentidos sobre a AIDS no incio da década de 80. Nos Estados Unidos, os primeiros casos da doença foram diagnosticados em homossexuais masculinos, 0 
que levou os médicos, respaldados pelos meios de comunicapä, a pensar no surgimento de um càncer gay. Denominaçao temporária escolhida na ocasiäo, já que näo se conhecia o agente causador da enfermidade. Mesmo quase 20 anos apís a descoberta da doença, o preconceito ainda se espalhava. A imprensa, dúbia, que atuava disseminando estereotipos, cumpria também outra funcäo: denunciava o preconceito. É a construçáo de sentidos. Segue texto de O Globo:

Vtimas do vrus do preconceito. Voluntários em teste de vacina contra a Aids sofrem discriminacio até de parentes e amigos. Nos últimos très anos, a vida de Paulo César Leonardo, um técnico em radiologia médica, de 46 anos, virou de ponta-cabeça. Ao primeiro golpe- a morte da mulher, em 6 de julho de 1994, vitima da Aids -seguiram-se trés picadas no braço que trouxeram para Paulo César o virus da desconfiança e do preconceito. Voluntário do primeiro programa no Brasil de testes de vacinas anti-HIV, ele conheceu o desprezo dos colegas de trabalho e se viu privado do contato com o filho do primeiro casamento de sua mulheros avís maternos do garoto de 9 anos, que têm a guarda do menino, proibiram até as conversas telefónicas. Confundido por muitos como um paciente da sindrome da imunodeficiéncia adquirida, Paulo César vem sentindo na propria pele o estigma e a discriminaca que cercam os portadores do HIV. (GIANOTTI, 1997, p.16).

Boa parte das primeiras reportagens da midia brasileira tinham como principal referència as agências norte-americanas de notcia, o que influenciou sobremaneira a forma como a doença chegou ao imaginário brasileiro. A imensa maioria dos primeiros pacientes com AIDS no Brasil, nos Estados Unidos e na Europa eram homossexuais masculinos e sobre eles recaiu o estigma da promiscuidade. "O preconceito e a intolerància estavam presentes nos discursos conservadores, nos quais se constró o termo aidético, categoria única, indivisivel e, principalmente, separada da sociedade." (DARDE, 2006, p.19). Na época, o termo ‘aidético' näo só era usado como significava um inimigo condenado à morte fsica, initil para 0 desenvolvimento social. "Justamente a estigmatizaça de pessoas e grupos infectados, estimulada pela construạo de sentidos da doença nos meios de comunicaba, desempenhou papel fundamental para a disseminaca do HIV/Aids na sociedade." (DARDE, 2006, p.19).

O Globo mostrava no ttulo de reportagem de 09 de abril de 1989, no caderno Rio, o estigma e as barreiras enfrentados pelos pacientes com HIV naquela época: 
"Aidéticos e a longa espera por um leito." (COHEN, 1989, p. 20). Espera por leitos reservados especificamente para os portadores da doença. Talvez fosse essa a solucajo encontrada por alguns profissionais de saide e autoridades, que isolavam os portadores do HIV. Isolamento que era fsico e social ao mesmo tempo.

O termo 'aidético', carregado de peso negativo, preconceituoso, excludente e discriminatório, juntava-se à segregạa imposta pela reserva de leitos especficos em hospitais. Havia, segundo a matéria de O Globo de 09 de abril de 1989, uma Central de Atendimento de Aidéticos, criada pela Secretaria de Saíde do Estado do Rio de Janeiro, que fazia a regulajá de leitos hospitalares para os pacientes infectados pelo HIV. Pacientes com outras enfermidades näo se misturavam aos aidéticos. "Através do telefone 590-5252, funciona a Central de Atendimento de Aidéticos, criada pela Secretaria de Saúde do Estado." (COHEN, 1989, p. 20).

Os pacientes aguardavam muito tempo por um leito e a chance de conseguir uma vaga em um hospital estava condiciona à morte de um paciente já internado.

Näo havia a possibilidade de melhora e de alta para casa? AIDS e morte se confundiam. Eram sinónimos. Como se vê no diálogo entre a repórter de O Globo e a atendente da Secretaria de Saíde:

Ali. Por favor, preciso internar com urgéncia um paciente portador de Aids. Em que hospital há vagas no momento? Em nenhum. Deixe o nome e os dados do paciente que nós vamos agendá-lo e ligaremos de volta quando vagar um leito. Mas quais sà as perspectivas? Varia muito. Hoje há quatro pacientes na frente. Temos que esperar que alguém morra para conseguir uma vaga. (COHEN, 1989, p. 20).

No contexto turbulento, denunciava-se que, na medicina privada, planos de saide paravam de pagar as despesas dos pacientes com HIV: "Quando é feito o diagnóstico da Aids, as empresas de medicina de grupo interrompem o seguro das despesas do paciente, apesar de serem obrigadas por resoluạo do Conselho Regional de Medicina a atender a todas as doenças." (COHEN, 1989, p.20).

Conforme Darde (2006), o primeiro caso brasileiro de AIDS foi notificado oficialmente em 1982, mas a doença tornou-se 'nacional' apis a morte do costureiro Marcos 
Vincius Resende Goncalves, o Markito, de 31 anos. O fato de os primeiros casos brasileiros também terem sido com homossexuais masculinos reforou a imagem do doente de AIDS trazida pela imprensa norte-americana. O Globo publicava, em 05 de junho de 1983, materia sobre o falecimento de Markito: "Costureiro Markito morre de 'cáncer gay' em Nova York”. O Globo informava que o criador da alta costura sensual e despojada, que vestia varias cantoras e atrizes brasileiras, tinha morrido, em Nova York, vitima da 'Sndrome da Deficiéncia Imunológica Adquirida', doença, entio, conhecida como 'cancer gay' por atacar principalmente homossexuais. É nitida a associaca entre homossexualidade e a enfermidade em questáo.

Figura (Acervo O Globo) - Costureiro Markito morre de 'cảncer-gay' em Nova lorque.

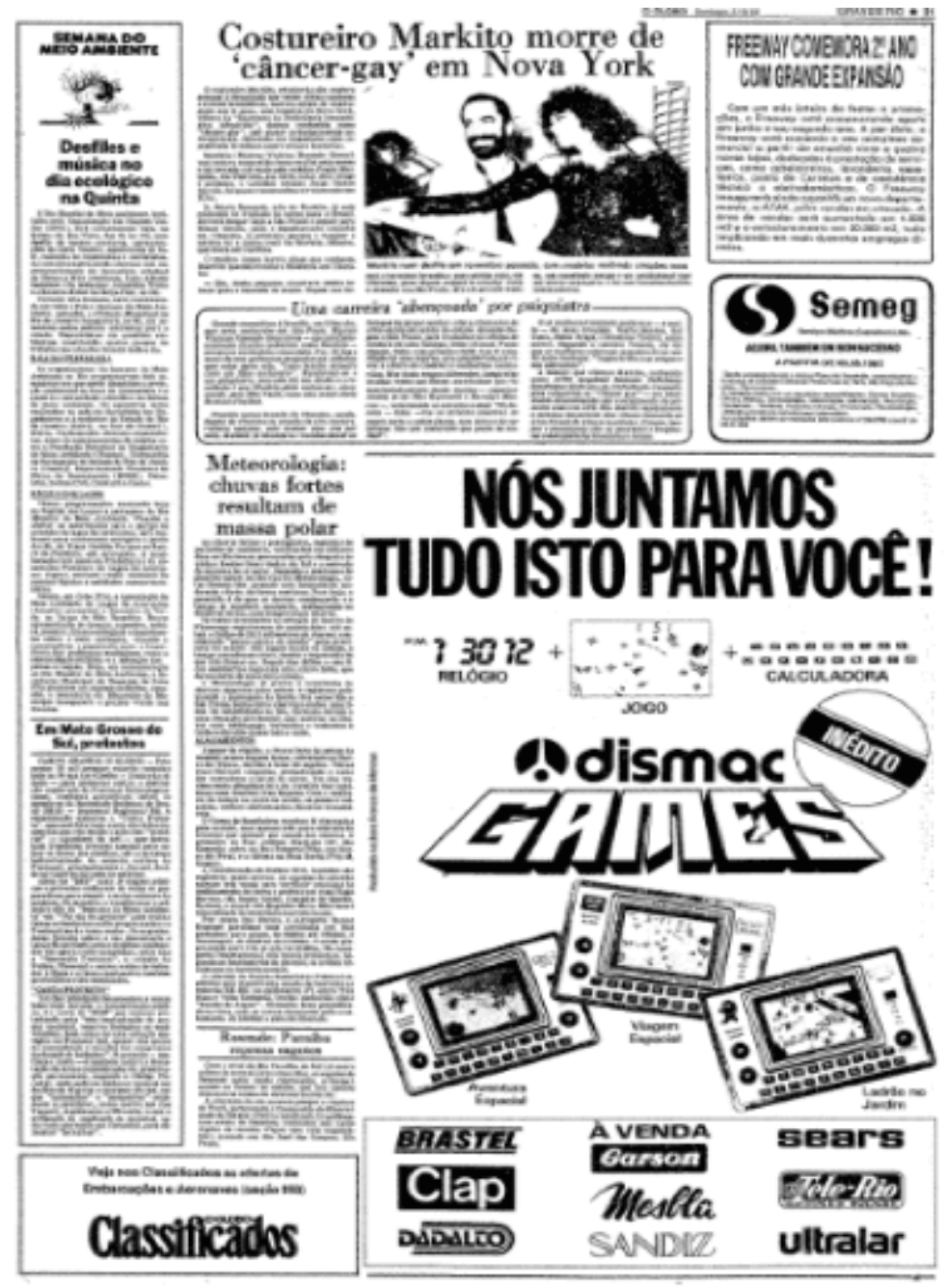


Em contrapartida, a divulgacáo de notcias sobre a AIDS pela midia brasileira possibilitou que a sociedade cobrasse uma atuaça mais enérgica e eficiente das autoridades nacionais. Organizạjes näo governamentais surgiram e o movimento homossexual ganhou projeca em matérias publicadas pelos veculos de imprensa. Segundo Darde (2006), no comero da epidemia no Brasil, a cobertura jornalstica baseou-se no material produzido por fontes e agèncias internacionais, por vezes, replicando o conteido marcado por desinformacăo e preconceito. Ainda de acordo com o autor, a procura pela identidade da AIDS mostrou, principalmente, o sofrimento de celebridades, como o cantor e compositor Cazuza.

As pessoas com HIV foram tratadas como objetos, estando alijadas da discussäo sobre os diversos aspectos da epidemia. Para Darde, a partir do nascimento das primeiras organizạjes näo-governamentais, em 1985, as pessoas vivendo com HIV começaram a ter voz própria, em oposiça à voz oficial do Estado. Questäo que é fundamental nos estudos do Jornalismo: a voz dos oprimidos, neste caso os doentes de AIDS, estava sempre em segundo plano, enquanto a fala oficial - do Estado e da Ciência - predominava no discurso jornalistico.

Materia de O Globo, publicada em 28 de outubro de 1990, pode ser usada para uma reflexä a respeito do que Darde propie e que foi relatado nos parágrafos anteriores. Em tal reportagem, Lucinha Araujo, mäe do cantor Cazuza, dá uma entrevista e fala sobre preconceito e desinformaça. O ttulo da reportagem é: 'Conscientizaça e respeito'. O Globo trata a AIDS como algo grave e dá voz a uma mulher da elite do Rio de Janeiro, maje de um artista de sucesso. Lucinha Araujo cobra das autoridades atitudes ou ạjes contra a doença. Isso fica claro quando a entrevistada responde à seguinte pergunta da jornalista Vera Lucas: "Como a senhora, que esteve em grandes centros internacionais de tratamento da Aids, analisa a situajo dos nossos hospitais?". A mäe de Cazuza assim responde:

é caótica. Os hospitais nảo têm dinheiro para comprar medicamentos, ampliar o número de leitos, pagar os profissionais especializados, nada. Näo sei se isso está ocorrendo por descaso das autoridades, mas tenho certeza de que o problema é da alçada do Governo Federal. Mas 
também náo podemos ficar esperando que o governo resolva tudo. Já está na hora de as empresas privadas ajudarem. (LUCAS, 1990, p. 7).

Lucinha Arajjo atua como interlocutora dos menos favorecidos, demonstra conhecimento sobre o assunto, trata-o com seriedade, mas náo se ouve o discurso dos vulneráveis, dos desvalidos. No trecho a seguir, verifica-se como Lucinha é anunciada: a máe dos anónimos aidéticos. "Depois de passar trís anos cuidando de Cazuza, Lucinha, cumprindo a promessa que fizera ao filho, transformou-se na mäe dos anónimos aidéticos pobres internados nos precários e desaparelhados hospitais brasileiros." (LUCAS, 1990, p.7).

O veculo de imprensa reconhece a existéncia de tais individuos, que náo sio ouvidos, porém náo dá espało a eles. Escolhe uma porta-voz, alguém conhecido, de destaque na sociedade da época, para falar em nome deles.

Pode-se acreditar que desde que uma pessoa com um estigma particular alcança uma alta posiço financeira, politica ou ocupacional dependendo a sua importáncia do grupo estigmatizado em questio - $\dot{\theta}$ possivel que a ela seja confiada uma nova carreira: a de representar a sua categoria. (GOFFMAN, 1963, p. 36).

A mảe de Cazuza náo tem AIDS e, portanto, náo carrega o estigma. Entretanto, apís a morte do filho, que contraiu doença, passou a destacar-se como uma representante das pessoas que viviam com o HIV, isto é, a elite consumidora do jornal se về representada e assustada, pois assistia ao avanço da doença que consideravam estar restrita ao mundo LGBT.

A parte da matéria que foi destacada acima carrega o estigma da pobreza e da fragilidade, que acompanha os pacientes diante da doença. Esse te o lado ressaltado: enfermos e subjugados, os pacientes estäo em má situạio, pois se encontram em instituipes hospitalares de má qualidade. Realidade dos doentes, que se deparavam com obstáculos que, por vezes, pareciam intransponveis. Mas si havia portadores do HIV entre os pobres? Os ricos náo ficavam doentes? Ocupando leitos de hospitais privados e com mais recursos, os pacientes ricos tinham outro cenário diante de si? Por terem posses, deparavam-se com menos preconceito? Por que nào dar voz aos oprimidos? 
Segundo SPINK (2001), em 30 de outubro de 1985, o jornal francés Le Figaro publicava: "A AIDS é a primeira doença da midia" frase que ressaltava um dos aspectos mais marcantes da epidemia - sua ampla difusio no mundo pelos veculos de comunicaja de massa - e a construạo de um novo fenómeno social: a AIDSnotcia. A AIDS tornou-se um fenómeno social marcado por tecnologias modernas no campo das pesquisas médicas, pelo ativismo social e pela impressionante dimensäo midiática que assumiu. Dimensäo expressa em números, conforme alega Spink: "de setembro de 1987 a dezembro de 1996, a Folha de Sảo Paulo publicou 7.074 matérias que, de alguma forma, faziam referência à AIDS; ou seja, ao longo de nove anos, foi publicada uma média de duas matérias por dia." (2001, p. 852).

Ainda segundo Spink (2001), a midia cumpre duas funçes: por um lado, a imprensa anunciou o aparecimento de um novo fenómeno no campo da patologia; e, por outro, definiu seus contornos e possibilitou a passagem das informaçes sobre a doença do dominio médico-cientfico para o registro social.

\section{CONSIDERAÇÕES FINAIS}

Os veculos de comunicaça influenciam costumes, ditam as pautas dos diálogos entre cidadíos e estäo presentes na retórica dos atores sociais: na contemporaneidade, a mdia assumiu um papel fundamental nos processos de produăo de sentidos, introduzindo transformạjes significativas nas práticas discursivas cotidianas.

A milia é uma vitrine, que expie informayjes, mas näo de maneira despretensiosa e aleatória. Influenciada por ideologias e interesses diversos, constitui um potente dispositivo que cria espacos de interacao. Tais espacos, sem fronteiras espaciais e temporais, permite-nos refletir sobre as dimensies éticas dos processos de informaçäo e comunicaçäo.

Um veículo de comunicação pode divulgar notcias sobre os mais variados assuntos, transitando pela ciência, pela saide, disseminando (pre)conceitos, ideias, imagens e estimulando o debate. Mas a quem cabe selecionar o que deve ou nảo ser publicado? 
Há pesquisadores que acreditam que, quando se trata de definir o conceito de notcia pelo interesse do leitor, os jornalistas se veem perdidos.

Toda a mobilizapa em torno do que publicar, da forma como se deve publicar e de como uma notcia deve ser escrita gera debates. A escolha do vocabulário das materias pie em confronto a luta em direpa à prevenço e ao tratamento das pessoas com HIV e o pensamento da sociedade ou de parte dela. As palavras tém muitos significados e podem representar ou simbolizar muita coisa. Há claros exemplos de mudança na linguagem dos textos que tratam da AIDS: prostitutas - hoje chamadas de profissionais do sexo; paciente/vtima da AIDS no lugar de aidético hoje, pessoa com AIDS; viciado ou drogado sendo substitudo por usuário de drogas. Em decorréncia das mudanças no contexto histórico, o caráter agressivo e sensacionalista da imprensa foi dando mais espą̧o ao viés politicamente correto.

\section{REFERÊNCIAS}

AIDS: entre estigma e pảnico cresce a incidência. 0 Globo, Rio de Janeiro, 30 jun. 1985. Caderno Grande Rio, $\quad$ p. 20. Disponvel em: http://acervo.oglobo.globo.com/busca/?tipoConteudo=pagina\&ordenacaoData=relevancia\&allwords=aids+e+estigma\&anyword=\&noword=\&exactword=\&decadaSelecionada=1980\&anoSelecionado=1985. Acesso em: 05 maio 2018.

BRASIL. Ministerio da Saide. Dermatologia na Atenção Básica de Saúde. Série Cadernos de Atenção Básica. Braslia, 2002, 142 p. Disponvel em:<http://bvsms.saude.gov.br/bvs/publicacoes/guiafinal9.pdf.> Acesso em: 17 abr. 2020.

BRASIL. Ministerio da Saide. Protocolo Clínico e Diretrizes para manejo da infeccão pelo HIV. Braslia, 2013, 416 p. Disponvel em: http://www.aids.gov.br/ptbr/pub/2013/protocolo-clinico-e-diretrizes-terapeuticas-para-manejo-da-infeccaopelo-hiv- em-adultos. Acesso em: 16 abr. 2020. 
BRASIL. Ministério da Saíde. Protocolo Clínico e Diretrizes para manejo da infeccão pelo HIV. Brasilia, 2018, 416 p. Disponível em: http://www.aids.gov.br/ptbr/tags/publicacoes/protocolo-clinico-e- diretrizes-terapeutica. Acesso em: 16 abr. 2020.

BERTOLA, Alexandra. Risco de Aids em transfusajo apavora pacientes. O Globo, Rio de Janeiro, 15 fev. 1987. Caderno. Grande Rio, p. 21. Disponivel em: 2http://acervo.oglobo.globo.com/busca/?tipoConteudo=pagina\&ordenacaoData=relevancia\&allwords=aids+e+transfusao\&anyword=\&noword=\&exactword=\&decadaSelecionada $=1980 \&$ anoSelecionado $=1987 \&$ mesSelecionado $=2$. Acesso em: 06 maio 2018.

CARNEIRO, Maria Luiza Tucci. O discurso da intolerància: Fontes para o estudo do racismo. In: CONGRESSO BRASILEIRO DE ARQUIVOLOGIA, 10., 1994, Säo Paulo. Anais... Sảo Paulo: Congresso Brasileiro de Arquivologia, 1994.

COHEN, Sandra. Aidéticos e a longa espera por um leito. O Globo, Rio de Janeiro, 09 abr. $1989 . \quad$ Caderno. Rio, 20. Disponivel em: C\%A4http://acervo.oglobo.globo.com/busca/?tipoConteudo=pagina\&ordenacaoData=relevancia\&allwords=aid\%C3\%A9ticos+e+leito\&anyword=\&noword=\&exactword=\&decadaSelecionada=1980\&anoSelecionado $=1989 \&$ mesSelecionado=4. Acesso em: 06 maio 2018.

Costureiro Markito morre de 'càncer-gay' em Nova York. O Globo, Rio de Janeiro, 5 jun. 1983.

DARDE, V. W. S. As representações de cidadania de gays, lésbicas, bissexu- ais, travestis e transexuais no discurso jornalístico da Folha e do Estadão. 2012. 230 f. Tese (Doutorado em comunicaño) - Faculdade de Biblioteconomia e Comunicaca, Universidade Federal do Rio Grande do Sul, Porto Alegre, 2012. Disponvel em: https://www.lume.ufrgs.br/bitstream/handle/10183/54524/000850909.pdf?sequence=1\&isAllowed=y. Acesso em: 17 abr. 2020. 
DIEHL, Leandro. et al. Prevaléncia da lipodistrofia associada ao HIV em pacientes ambulatoriais brasileiros: relacio com sndrome metabólica e fatores de risco cardiovascular. Arquivo Brasileiro de Endocrinologia Metabólica, Sảo Paulo, 52(\, n. 4, p. 658-667, jun. 2008. Disponvel em: http://saudepublica.bvs.br/pesquisa/resource/pt/lil-485832. Acesso em: 15 abr. 2020.

GALLIAN, Dante Marcello Claramonte. A (re) humanização da medicina. [2001]. Centro de Historia e Filosofia das Cièncias da Saide da Unifesp-EPM. Disponvel em:<http://www2.unifesp.br/dpsiq/polbr/ppm/especial02a.htm>. Acesso em: 20 mar. 2020.

GOMES, Antonio Marcos Tosoli; SILVA, Érika Machado Pinto; OLIVEIRA, Denize Cristina de. Representapes sociais da AIDS para pessoas que vivem com HIV e suas interfaces cotidianas. Revista Latino-Americana de Enfermagem, Ribeiräo Preto, v. 19, n. $3, \quad$ p. 485-492, jun. 2011. Disponvel em: <http://www.scielo.br/scielo.php?script=sci_arttext\&pid=S010411692011000300006\&lng=en\&nrm=iso $>$. Acesso em: 17 abr. 2020

GOFFMAN, Erving. Estigma: notas sobre a manipulaçao da identidade deterio- rada. 4. ed. Rio de Janeiro: Zahar, 1982. 158 p.

GIANOTTI, Rolland. V'timas do virus do preconceito. O Globo, Rio de Janeiro, 09 abr. 1997. Caderno Rio, p. 16. Disponvel em: http://acervo.oglobo.globo.com/busca/?tipoConteudo=pagina\&ordenacaoData=relevancia\&allwords=virus+do+preconceito\&anyword=\&noword=\&exactword=\&decadaSelecionada=1990\&anoSelecionado=1997. Acesso em: 05 maio 2018 .

HEUSI nảo punirá legistas que se negam a necropsiar os aidéticos. O Globo, Rio de Janeiro, 24 jun. 1987. Caderno Grande Rio, p. 9. Disponvel em:<http://acervo.oglobo.globo.com/busca/?tipoConteudo=pagina\&ordenacaoData=relevancia\&allwords=heusi+e+legistas\&anyword=\&noword=\&exactword=\&decadaSelecionada=1980 > . Acesso em: 06 maio 2018. 
JORGE, Thas de mendonça. Valor-notcia provoca polemica. In: Manual do Foca: guia de sobrevivência para jornalistas. Sio Paulo: Contexto, 2015. p. 27- 38.

LOPES, Antônio Carlos. Relação médico - paciente: humanizaạo è fundamental. Sociedade Brasileira Clnica Médica [Site]. Disponvel em: http://www.sbcm.org.br/v2/index.php/artigo/2038-relacao-medico-paciente-humanizacao-e-fundamental. Acesso em: 15 abr. 2020.

LOBATO, Eliane. Nem tudo é drama. O Globo, Rio de Janeiro, 12 jun. 1987. Segundo Caderno, p. 5. Disponvel em: C\%A6http://acervo.oglobo.globo.com/busca/?tipoConteudo=pagina\&ordenacaoData=relevancia\&allwords=nem+tudo $+\% C 3 \% A 9+$ drama\&anyword=\&noword=\&exactword $=\& d e-$ cadaSelecionada $=1980 \&$ anoSelecionado $=1987 \&$ mesSelecionado $=6 \&$ diaSelecio nado=12. Acesso em: 05 maio 2018.

LUCAS, Vera. Conscientizacio e respeito. O Globo, Rio de Janeiro, 28 out. 1990. Cad. Segundo Caderno, p. 7. Disponvel em: http://acervo.oglobo.globo.com/busca/?tipoConteudo=pagina\&ordenacaoData=relevancia\&allwords=lucinha+araujo\&anyword=\&noword=\&exactword=\&decadaSelecionada=1990\&anoSelecionado=1990\&mesSelecionado=10. Acesso em: 06 maio 2018 .

MARQUES, Maria Cristina da Costa. Saide e poder: a emergéncia poltica da Aids/HIV no Brasil. História, Ciências, Saúde, Rio de Janeiro, v. 9, p. 42-65, 2002. Suplemento. Disponvel em:<http://www.scielo.br/pdf/hcsm/v9s0/02.pdf.>. Acesso em: 21 set. 2017.

SEIDL, Eliane Maria Fleury; machado, Ana Cláudia Almeida. Bem-estar psicológico, enfrentamento e lipodistrofia em pessoas vivendo com HIV/AIDS. Psicologia em Estudo, Maringá, v. 13, n. 2, p. 239-247, abr./jun.2008. Disponvel em:<http://www.scielo.br/pdf/pe/v13n2/a06v13n2>. Acesso em: 21 set. 2017.

SPINK, Mary Jane. et al. A construpao da AIDS-notcia. Cad. Saúde Pública, Rio de Janeiro, v. 17, n, 4, p. 851-862, jul./-ago. 2001. Disponvel em: https://www.re- 
searchgate.net/profile/Mary_Spink/publication/26359601_A_construcao_da_AIDSnoticia/links/540f63d90cf2f2b29a3ddd9e.pdf. Acesso em: 16 abr. 2020.

ZYGLAND, Fanny. Famlias rejeitam doentes com Aids. O Globo, Rio de Janeiro, 29 maio 1988. Caderno O Pas, p. 10. Disponivel em: http://acervo.oglobo.globo.com/busca/?busca=fanny+zygland. Acesso em: 06 maio 2018.

\section{APÊNDICE - REFERÊNCIAS DE NOTA DE RODAPÉ}

4. Aqui, aparece o rótulo. É com esse peso que se atribui a positividade de um teste anti-HIV. Peso maior pode recair sobre o individuo que recebe o diagnistico. Estigma e discriminạa podem acompanhar tal situặo, levando à elaboraต̣o de uma sentenca: portar uma doença crónica, cercada de medo e ainda sem cura.

5. A instituigạo da terapia antirretroviral (TARV) tem por objetivo diminuir a morbidade e mortalidade das pessoas vivendo com HIV/AIDS (PVHA), melhorando a qualidade e a expectativa de vida.

Enviado: Abril, 2020.

Aprovado: Agosto, 2020. 